[63]

\title{
LA AGRICULTURA DE LOS \\ COSECHERO-EXPORTADORES DE TOMATE \\ DE INVIERNO EN ALACANT
}

\author{
José Costa Mas
}

*Este trabajo ha sido realizado dentro de los planes de investigación de la Comisión Asesora Científica y Técnica.

\section{PANORAMA GENERAL}

La figura del cosechero-exportador ha cobrado considerable relevancia en el área meridional del País Valenciano durante las últimas tres décadas. Dentro de la provincia de Alacant su actuación se centra casi exclusivamente en las comarcas del sur, en especial las del Camp d'Alacant, Bajo Segura, Camp d'Elx y Vinalopó Mitjà, debido a que éstas reúnen dos condiciones: una gran benignidad térmica y disponibilidad de agua -bien que con apreturas-, esenciales ambas para la obtención, fuera de temporada, de una serie de productos que, precisamente por las fechas en que se recolectan, alcanzan estima y cotización en los mercados extranjeros. Se trata de unas comarcas, un clima y unas producciones que, en cierto modo, tienen su natural inserción en el conjunto del sureste peninsular, pues se prolongan, casi sin solución de continuidad, por las provincias de Murcia y Almería, en las que, por cierto, también operan varias de las empresas del ramo que tienen intereses en Alacant.

Los cosecheros exportadores de esta provincia están encuadrados en tres Asociaciones Provinciales: las del tomate de invierno, alcachofa y uva de mesa, a tenor de su dedicación exclusiva o primordial. A menudo el empresario se especializa en uno de estos cultivos, pero la casuística es muy variada, pues existen firmas que se dedican al menos a dos de ellos, las hay que cosechan otras hortalizas y/o frutas, y están las que, por añadidura, o incluso como ocupación básica, comercializan producciones ajenas.

El presente artículo centra la atención exclusivamente en la actividad agrícola -y sus repercusiones de orden espacial y paisajístico- que llevan a cabo las empresas particulares orientadas en especial al tomate de invierno [64] (conocidas popularmente por las «compañías» o los «tomateros»). Por lo que atañe a la vertiente comercial, remitimos al lector a la bibliografía relacionada al final, en la que también se hallan algunas consideraciones de orden económico.

En realidad son los tomateros quienes más se ajustan al concepto de cosechero-exportador; todos ellos mantienen esa doble faceta, bien que alguno dé salida a su cosecha a través de otra firma o que otro se vea obligado a completar su cupo de exportación comprando mercancía. Es más, ellos cultivan la práctica totalidad del tomate de invierno, el grueso a cargo de las firmas particulares y el resto por agricultores encuadrados en grupos cooperativos facultados para comercializarlo. Por contra, en uva de mesa y en alcachofa es mayor la disociación entre el productor y el exportador.

El cultivo del tomate había arraigado ya, al menos desde los años veinte, entre los campesinos de L'Horta d'Alacant, con variedades autóctonas, entre ellas una de invierno (la «mutxamel»). A partir de 1950-51 se introduce en L'Horta y en Novelda el tomate llamado «canario» o «inglés», cuyo cultivo pronto monopolizan los cosecheros exportadores, en cuyo origen hay comerciantes -y también algún agricultor- en su mayoría valencianos, catalanes y canarios, que se asientan en esta zona. Algunos acudieron con miras a obtener rápidos beneficios y no tuvieron continuidad, pero los que permanecieron constituyen una auténtica élite dentro del sector. 
Muchas otras firmas tomateras han ido proliferando en base a iniciativas autóctonas, en ocasiones a cargo de agricultores que, aun partiendo de una posición modesta, apoyándose en créditos bancarios, han transgredido las barreras que suelen impedir el paso del campesino medio o pequeño a la moderna empresa integral, y ello merced a que, en el sector tomatero, la concentración de medios de producción y del circuito de ventas se opera sin el concurso de una base territorial en propiedad, dado que la superficie de explotación se reúne mediante el sistema de arrendamiento.

Con todo, en líneas generales el agricultor familiar, cultivador directo y personal, falto de apoyos para organizarse y comercializar en común, quedó marginado de este proceso durante la etapa de despegue y perdió el tren de la exportación directa, a la que sólo acceden hoy, casi siempre en cuantía parca y constreñidas por el sistema de contingentación, algunas Cooperativas y Sociedades Agrarias de Transformación.

Estas agrupaciones para la exportación en común apenas representan el 11\% de los 52 miembros de la Asociación Provincial de tomateros, integrada en un 40\% por sociedades anónimas y limitadas, cuyos almacenes radican de preferencia en Alacant y su comarca y en Novelda, las cuales controlan la mayor parte del negocio. Entre los asociados hay muchos del Bajo Segura, aunque en su mayoría son casi exclusivamente comerciantes (apenas cultivan algunas tahúllas); también los hay de Elx, e incluso de otras provincias, pero que poseen cupo de exportación en ésta.

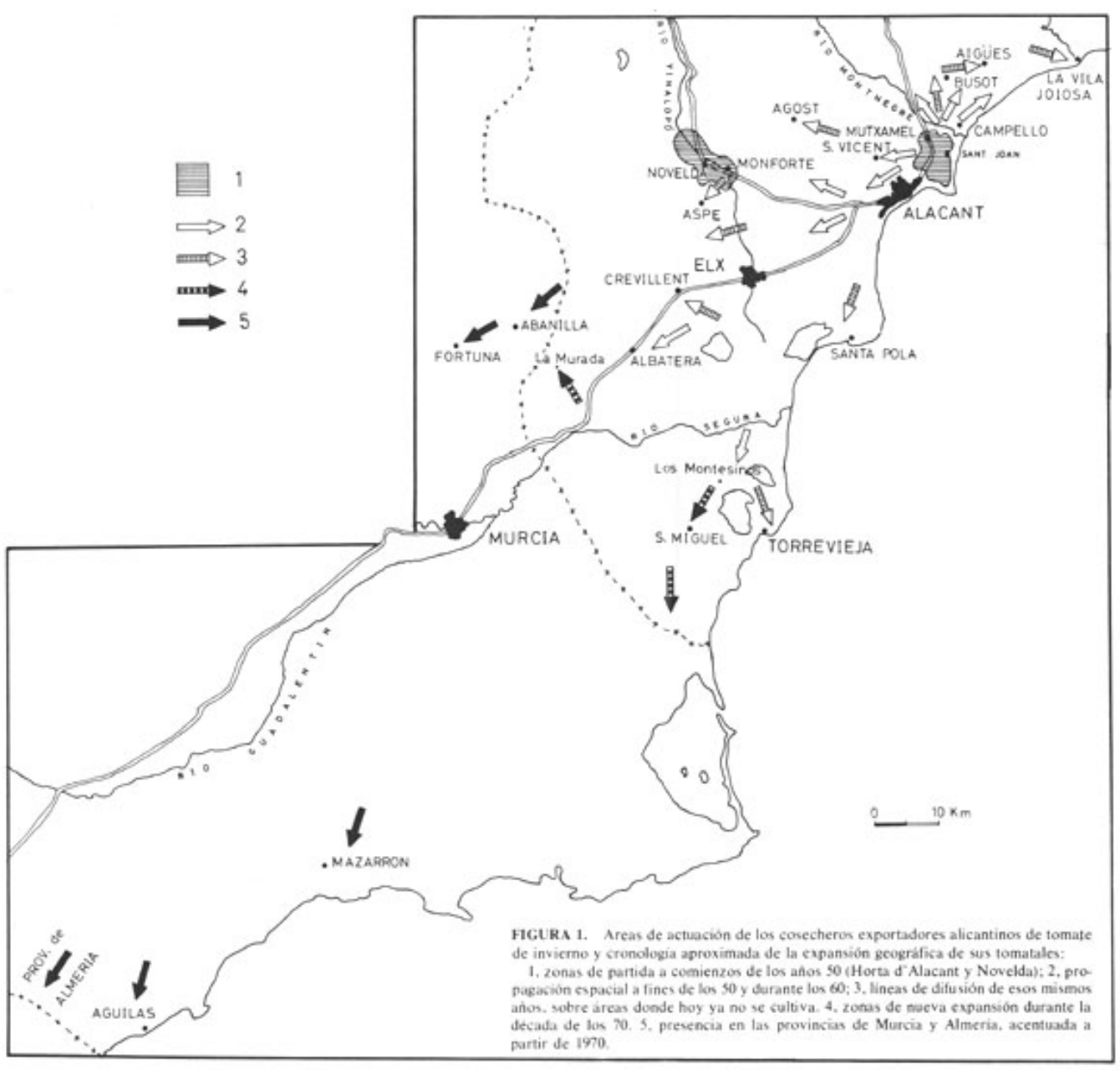


Varias de las compañías más importantes que actúan en Alacant constituyen, de hecho, parte integrante de vastos conglomerados o grupos empresariales del ramo comercial hortofrutícola que, por ventajas de índole operativa y fiscal, adoptan diferentes personalidades jurídicas en cada ámbito de actuación. A menudo abarcan una gran diversidad de intereses -comercio y cultivo de cítricos, de otros frutales y hortalizas varias- sobre un amplio abanico espacial: València, Alacant, Murcia, Almería, e incluso en dos de los casos, también en Barcelona y Canarias.

La exportación del tomate de ciclo otoño-invierno ha estado tradicionalmente intervenida por la Administración. Tan sólo podían expedirlo las firmas que poseían una cuota o cupo determinado -objeto de especulación- y para proteger la producción canaria, después del 31 de enero no se permitía la salida del tomate liso (o «canario») peninsular, bien que el tomate asurcado (o «mutxamel») tenía licencia hasta el 30 de abril. Esta distinción fue borrada al introducirse los tomates híbridos, al tiempo que se multiplicaba la producción de la península, por lo que hubo de cambiar el sistema. En 1979 se arbitra una campaña única que, desde 1981, se prolonga hasta el 20 de mayo, englobando la cosecha de media estación. Actualmente se parte del principio de libre exportación, aunque de hecho, cuando los precios bajan en exceso, una comisión la autorregula y contingenta en función del precedente exportador de las firmas, lo que mantiene la vigencia de los antiguos cupos.

Después de algún año con precios poco remuneradores, la mayor flexibilidad con que se enfocan las campañas de exportación, unida al alza de los costes de la producción de invernadero entre los competidores europeos en función de la crisis energética, han propiciado que el tomate español alcanzase muy buenos resultados en 1982-83, campaña en la cual la exportación alicantina ascendió a 71.400 Tm (unos $2 / 3$ de la producción), en un 70\% expedidas antes del 1 de febrero, con destino al Mercado Común y países del norte de Europa.

La exportación en régimen libre puede beneficiar en especial a las Cooperativas y Sociedades Agrarias de Transformación, las cuales antaño, para poder exportar, tenían que buscar en el mercado negro el correspondiente cupo de exportación. Con todo, para los agricultores de tipo familiar así encuadrados el panorama no acaba de clarificarse: en Mazarrón (Murcia), durante el presente octubre, ese escalón de productores se ha encontrado con $600 \mathrm{Tm}$ de fruto sin salida y ha desatado una llamada «guerra del tomate» contra una normativa de contingentaciones que prima a los grandes exportadores de siempre.

La agricultura practicada por los cosecheros exportadores se encuadra entre los sectores más dinámicos del campo alicantino; en general y, sobre todo en la última década, la innovación tecnológica ha sido un fenómeno de constante incidencia, que deja rápidamente obsoletas variedades, técnicas y [66] modos de producción; aunque no en todos los casos y circunstancias, pues, como se verá, el tradicional recurso al cultivo itinerante -con cambio anual de parcela- ha ofrecido serias resistencias a la sedentarización de los tomatales, aun siendo ésta plenamente viable desde hace no menos de siete años.

$\mathrm{Y}$ es que existe de hecho una gran heterogeneidad de situaciones, que van desde la sociedad altamente capitalizada, titular de haciendas, bien equipada y tecnificada, con fuertes inversiones en capital fijo y una organización modélica que ha asimilado la moderna gestión empresarial, hasta la pequeña empresa, nacida al calor de una coyuntura favorable, pero carente de todo lo anterior, con constantes agobios de numerario y que, a veces, se extingue o cae en la dependencia de las grandes.

Las empresas más fuertes y dinámicas son las que han marcado la pauta de la sedentarización del cultivo, bien que algunas la compaginan con la vieja trashumancia cultural, ávida colonizadora de tierras vírgenes. Son también las que pueden optimizar el tamaño de las 
explotaciones y generar interesantes economías de escala, las que recurren a masivos insumos y elevan progresivamente el umbral tecnológico y científico (bien que, a menudo, en dependencia respecto al extranjero, como en el caso de las semillas), y las que, por ende, maximizan los rendimientos unitarios y la producción en masa. Pero a partir de estas firmas de vanguardia, algunos de esos rasgos se han ido difundiendo, a modo de efecto de arrastre, entre el resto de los cosecheros exportadores.

Los caracteres más comunes a todo el sector son el fuerte peso del trabajo manual que, pese a los avances tecnológicos, sigue exigiendo el cultivo del tomate (mano de obra abundante y barata, tradicionalmente reclutada a base de migraciones temporales) y la integración vertical a nivel de empresa, que abarca desde los procesos de transformación de tierras y su cultivo hasta el manipulado de la mercancía y su comercialización.

Es de destacar el hecho de que las compañías han venido practicando el cultivo del tomate de invierno en régimen de itinerancia, cambiando cada año -o cada dos- la plantación de una parcela a otra, lo que se acompañó de una gran movilidad geográfica. Pero desde hace unos siete años se va imponiendo la sedentarización de los tomatales, que se fijan permanentemente sobre el mismo campo; el proceso de fijación al principio fue asumido lentamente por contadas sociedades -las más fuertes económicamente- pero se está generalizando con extrema rapidez, sobre todo en las últimas dos campañas.

Los costos de producción del tomate de invierno son muy considerables, precisando grandes inversiones. La tabla siguiente, aunque incluye informaciones no verificadas y de fuentes dispares, es indicativa, grosso modo y a nuestro entender, de la evolución de esos costos en las últimas dos décadas.

La última columna refiere los costos de una firma que en la campaña 1980-81 cultivó 40 ha de tomate, la mayor parte en Alacant, en una gran finca arrendada donde hasta hace dos años escalonaba las plantaciones, cambiando [67] anualmente de parcelas, con utilización del riego a manta. Los costos incluyen la roturación y preparación de las tierras, así como las obras y canalizaciones que era necesario realizar para la campaña. Aunque se trata de un caso significativo, esos costos no son generalizables, habría que contrastarlos con los de alguna explotación en régimen sedentario.

\section{COSTOS DE PRODUCCIÓN APROXIMADOS POR TAHÚLLA DE $1.000 \mathrm{~m}^{2}$}

\section{Campaña 1961-62 Campaña 1971-72 Campaña 1980-81}

$\begin{array}{llrlrlr}\text { Conceptos } & \text { Ptas. } & \mathbf{\%} & \text { Ptas. } & \text { \% } & \text { Ptas. } & \text { \% } \\ & & & & & & \\ \text { Jornales y sueldos } & 7.546 & 48,5 & 15.400 & 47,6 & 105.765 & 65,9 \\ \text { Abonos e insecticidas } & 3.668 & 23,6 & 6.936 & 21,4 & 26.344 & 16,4 \\ \text { Agua de riego } & 1.459 & 9,4 & 2.497 & 7,7 & 8.269 & 5,2 \\ \text { Arrendamiento de la tierra } & 979 & 6,3 & 2.000 & 6,2 & 4.558 & 2,8 \\ \text { Otros capítulos } & 1.909 & 12,2 & 5.537 & 17,1 & 15.485 & 9,7 \\ \text { GASTOS TOTALES } & \mathbf{1 5 . 5 6 2} & \mathbf{1 0 0 , 0} & \mathbf{3 2 . 3 7 0} & \mathbf{1 0 0 , 0} & \mathbf{1 6 0 . 4 2 5} \mathbf{1 0 0 , 0} \\ \text { Tomate cosechado (Kg.) } & 4.405 & & 6.600 & & 12.000 \mathrm{ca} . \\ \text { Costo unitario (ptas./Kg.) } & 3,53 & & 4,76 & & 13,36 \mathrm{ca} .\end{array}$

Fuente: Para 1961-62, vid. NAVARRO SALA, J. A., pág. 65; y para 1971-72, vid. Gabinete Técnico del Consejo Económico-Social, pág. 41 (op. cit. en bibliografía final).

En la tabla precedente se observa un progresivo aumento de los gastos que, si se duplican en los años sesenta, alcanzan a quintuplicarse en la última década. Con todo, hay que considerar 
el fuerte aumento de los rendimientos unitarios que, aunque no llega a compensar la aceleración del gasto, sí contribuyen a aminorar su incidencia sobre el precio de costo del tomate; aun así, éste es casi tres veces mayor que diez años atrás.

El encarecimiento se da en todos los capítulos, pero es máximo en lo que se refiere a mano de obra, la cual supone ahora cerca de dos tercios de los gastos globales. Se observa también que el factor tierra, en régimen de alquiler, es el que menos peso relativo presenta, y tampoco es relevante la participación porcentual del agua de riego. La inversión global es muy cuantiosa, del orden de 1,6 millones de pesetas por hectárea.

Aparte habría que considerar el manipulado y envasado del fruto, así como su expedición al mercado. Nótese también que no se ha tenido en cuenta el capítulo de la financiación, cada vez más importante por la carestía del dinero y por cuanto que muchas firmas recurren al crédito.

A tenor de las apreciaciones de superficies cultivadas, referentes al último trienio, la comarca del Camp d'Alacant concentra el grueso de las plantaciones provinciales de tomate de invierno, entre el 71\% y el 78\% según campañas, en especial en los términos de Mutxamel, El Campello y Alacant. Le sigue el Bajo Segura, que cifra del 23\% al 17\%, destacando el municipio de [68] Orihuela; el Baix Vinalopó -o Camp d'Elx- y Novelda localizan el 5\% ó 6\% restante.

La extensión global no se conoce con certidumbre; debe oscilar entre 700 y 600 ha, con tendencia a contraer las plantaciones en tanto en cuanto el rápido incremento de los rendimientos unitarios permite cubrir ampliamente los cupos de exportación con cada vez menores superficies de cultivo. A título indicativo, si con el tomate «canario» se producían por el año 1970 entre 5 y $6 \mathrm{Kg} / \mathrm{m}^{2}$ con puntas excepcionales de hasta $7,5 \mathrm{Kg}$, actualmente con las variedades híbridas se obtienen de 11 a $12 \mathrm{Kg} / \mathrm{m}^{2}$ si el riego es a manta, alcanzándose hasta los $15 \mathrm{Kg} / \mathrm{m}^{2}$ con riego localizado por goteo, y aún más si el cultivo es protegido en invernadero. El tomatero está siempre pendiente de las últimas novedades que la agrotecnología extranjera ofrece en semillas selectas, de productividad creciente.

Además de lo cultivado en la provincia, las firmas de mayor fuste entre las radicadas en Alacant cosechan importantes volúmenes de tomate en dos zonas murcianas, las de Águilas-Mazarrón y Fortuna-Abanilla, así como en diversas áreas de la provincia de Almería; en ésta, y también en Águilas, cobra gran interés el tomate de invernadero.

\section{LOS CONDICIONAMIENTOS FÍSICOS}

La agricultura del tomate de invierno, por lo que respecta a la provincia de Alacant, se ha desarrollado estrictamente en su extremo meridional, sobre los llamados llanos litorales que, en buena parte, son prolongación fisiográfica de la depresión prelitoral murciana. En efecto, se desenvuelve en una franja próxima al Mediterráneo, por debajo de la isohipsa de los 200 metros, extendida al sur del paralelo de La Vila Joiosa, la cual tiene por centro neurálgico la comarca del Camp d'Alacant, que ha sido y es la zona tomatera por excelencia. Aunque sin la amplitud y relativa continuidad que cobra en ésta, el tomate de invierno también se extiende por áreas del Bajo Segura, del Baix Vinalopó y, ya muy secundariamente -aunque fue uno de los puntos de arranque de este cultivo-, por la zona de Novelda (Vinalopó Mitjà).

La caracterización térmica de este ámbito es muy favorable para que pueda sustentar los cultivos delicados, de fuera de estación, que practica el cosechero-exportador. En el dominio litoral, atemperado por la influencia marítima, donde la insolación registra valores próximos a las 3.000 horas al año, las temperaturas medias anuales rondan los $18^{\circ}$, como en Alacant, o los superan, como es el caso de Orihuela, con 18,4 $4^{\circ}$; Novelda, a unos $25 \mathrm{Km}$ de la costa, aún promedia $17,2^{\circ}$. El mayor privilegio agroclimático estriba en la bonanza invernal, que atestiguan los altos registros térmicos del mes más frío, el cual promedia $11,4^{\circ}, 10,6^{\circ}$ y $10,3^{\circ}$, 
respectivamente, en las tres estaciones citadas, y es muy significativo que la media de las mínimas de enero alcance los $6,2^{\circ}$ en Alacant. Las temperaturas, pues, pocas veces descienden al punto de alterar el desarrollo vegetativo esperado en el tomate de invierno, y la cuantía e intensidad de las heladas son exiguas, aunque las que acompañan a [69] las olas de frío generales suponen un grave riesgo por su devastadora incidencia sobre las plantaciones de tomate, también sujetas a ocasionales, y no menos dañinas, granizadas.

Lo cierto es que las compañías, a la hora de escoger la ubicación de los tomatales, por encima de cualquier consideración valoran el microclima del lugar; un buen suelo «sin clima» -opinan- pierde toda estimación. E incluso, aquilatando cuidadosamente los inconvenientes y las ventajas, procuran armonizar las inherentes a las economías de escala, que operan a favor de la concentración de las plantaciones, con una estrategia tendente a diluir la incertidumbre climatológica a base de diversificar los campos de cultivo entre zonas geográficas que guarden una prudencial separación.

Desde la perspectiva de la pluviometría este dominio costero surestino se caracteriza por una acusada indigencia, a la que se añade una fuerte irregularidad interanual. Las precipitaciones oscilan por lo general entre 300 y 350 mm (Orihuela, 294; Novelda, 309; La Vila Joiosa, 335; Alacant, 348), e incluso descienden a unos $280 \mathrm{~mm}$, o menos, en ciertas áreas (Guardamar, 287; Monforte, 282; Torrevieja, 245).

Estas estaciones presentan los clásicos máximos equinocciales, con pico acentuado en el otoñal que, centrado en octubre, se vincula a violentos aguaceros de gran intensidad horaria, generados por procesos de gota fría cuando éstos coinciden con altas tensiones de vapor. Al año, tan sólo se registran entre 30 y 40 días de precipitación (y aún menos, 26 días, en Guardamar y Monforte). La nubosidad es reducida, incluso junto al mismo mar: Alacant cuenta con 190 días despejados al año.

Precipitaciones escasas y temperaturas altas son determinantes de una generalizada aridez climática que, con cierta frecuencia, se ve reforzada por la aridez edáfica, como la que acompaña al dominio de las margas sobre una parte del territorio en el que operan los tomateros. La evapotranspiración potencial es elevada, más de $900 \mathrm{~mm}$ anuales, y toda la zona se encuadra dentro del clima seco según Thornthwaite; en su variante semiárida figuran el Camp d'Alacant y las cuencas media y baja del Vinalopó, que presentan entre 560 y $600 \mathrm{~mm}$ de déficit hídrico y nueve meses áridos; mientras que el subtipo árido se extiende por el Bajo Segura, con déficits más acentuados (668 mm en Orihuela).

Se comprende, pues, que para el cultivo del tomate, aun el de estación invernal, sea imprescindible -como para tantos otros aprovechamientos- unos aportes de agua importantes, de orden mucho más que suplementario, mediante el regadío, con el que el cosechero- exportador, superando la resistencia ecológica, ha contribuido a redimir -ya temporal, ya definitivamenteamplios secanos y eriales desheredados.

En estas condiciones de aridez los llanos litorales se caracterizan por una vegetación natural rala y discontinua. La vida vegetal en las zonas de actuación de las compañías es escasa y de marcado carácter xérico, con predominio del matorral árido seudoestepario, representado por la asociación Chamaeropideto Rhamnetum, [70] en formación abierta y de poca altura, y sobre todo por la alianza Thymo-Siderition, cuyo máximo exponente es un tomillar claro, muy laxo, como forma degenerada del matorral anterior.

Aunque lo determinante sea el microclima y la disponibilidad de aguas para el riego, no cabe olvidar que hay una tercera variable en juego, cual es el suelo. La estrategia de los cosecheros exportadores ha consistido, a nuestro juicio, en la colonización de las tierras de mayor aptitud agrícola, bien que tuvieron que escogerlas entre aquéllas que, tras la ocupación previa de los mejores terrenos por otros agentes y cultivos, se podrían considerar como residuales. Pero entre éstas se cuentan muchas tierras de buena condición edáfica, cuyo 
aprovechamiento racional había sido obstaculizado por la dificultad de acceder a los recursos hídricos imprescindibles para transformarlas en regadíos.

En el Camp d'Alacant, durante una primera etapa, las compañías actuaron sobre excelentes terrenos de aluvión que tapizan los glacis-terrazas de L'Horta, a menudo en coexistencia con el arbolado allí en cultivo, reafirmando con ello el carácter de huerta semiarbolada, con aprovechamiento herbáceo del suelo en promiscuidad, que caracterizó tradicionalmente a L'Horta d'Alacant. Con posterioridad, los tomateros han ido colonizando una serie de vaguadas, que eran yermos y secanos, formadas en la llamada cuenca de Busot por los afluentes del río Montnegre (barrancos de la Torre, Vergeret, Aigua Amarga y Cabrafic) y separadas entre sí por alineaciones montañosas de escasa envergadura; dentro de este ámbito fisiográfico, mucho más heterogéneo que el vecino llano aluvial de L'Horta, los tomatales han ocupado, además de algunos retazos de terrazas fluviales (como las del Vergeret y parte del Montnegre), las amplias superficies de los glacis de acumulación, articuladas en campos que descienden en gradería hasta colgar sobre los cauces encajados. La toponimia de los parajes apropiados por las firmas es bien elocuente: El Fondó, Foia de l'Enguerino, Bonalba Baixa, el mismo Vergeret (pequeño vergel), etc.; se trata, por consiguiente, de las tierras bajas, de suelo más profundo y con desniveles moderados.

Simultáneamente, y también dentro del Camp d'Alacant, su actuación se ha extendido sobre las cañadas y sectores de glacis de Sant Vicent del Raspeig (Baiona Baixa, Pla de Conxeta...) y de la parte oriental del término d'Alacant (Bacarot, Rebolledo, La Vallonga, Fontcalent, L'Alcoraia, La Canyada). En una zona vecina a ésta, pero ya en término de Elx, se han instalado en condiciones fisiográficas parejas (Torrellano, El Fondet dels Pinyols).

La acción colonizadora de los glacis de acumulación ha sido una constante, también en las otras comarcas, como en el área de Novelda y, sobre todo, en el campo del Bajo Segura, donde alternan suelos pedregosos y de textura fina sobre costras de distinta compacidad; en el sector interior o glacis de La Murada-Albatera-Crevillent apenas hay encostramientos, mientras que en el litoral, desde Torrevieja a La Horadada aparecen costras potentes, más o menos desmanteladas a veces, las cuales son levantadas durante los procesos de bonificación agrícola. 


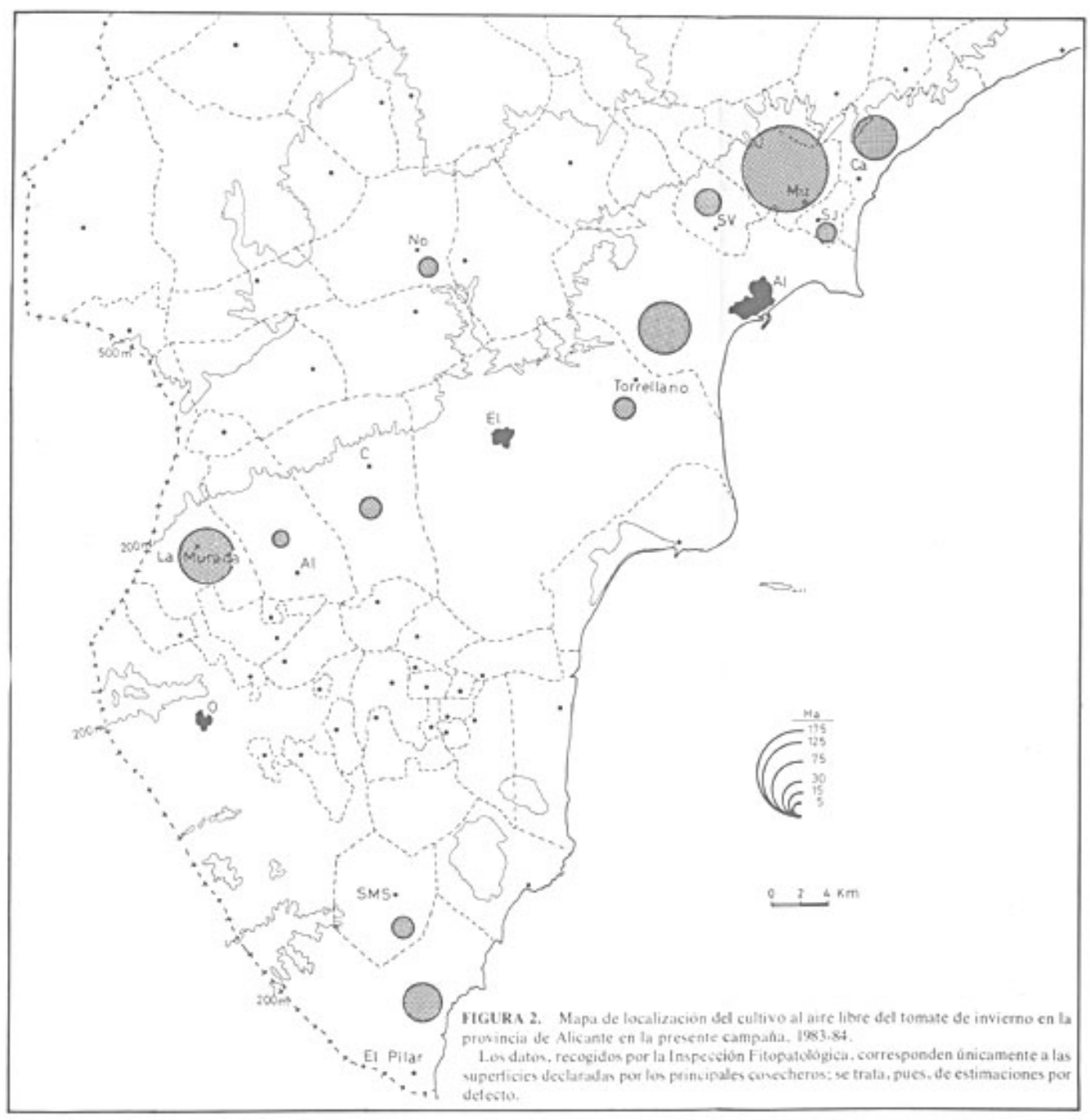

[71]

Un análisis de los suelos de El Vergeret (Alacant) los describe como franco-arcilloso-arenosos, de consistencia media -como conviene al tomate-, con reacción alcalina ( $\mathrm{pH}$ entre 7'4 y 7'6), abundancia de carbonato cálcico y nivel bajo de nitrógeno. Puede ser un tipo de suelo bastante expresivo, aun dentro de la heterogeneidad de situaciones, de los que tapizan la zona tomatera alicantina.

Los únicos suelos que rehuyen las compañías son los muy compactos y de difícil drenaje, y los salinos o muy vulnerables a la salinización.

Con todo, muchos tomateros se lamentan de la pobreza de los suelos que usualmente trabajan, a la que a menudo ellos han contribuido, acelerando su degradación, debido a la práctica de largas barbecheras que exponen los suelos desnudos a la denudación. En cualquier caso, las empresas no escatiman a la hora de aportarles fertilizantes, tanto orgánicos -la clásica estercoladura- como minerales: prácticamente «crean» un suelo nuevo, lo antropizan de lleno.

DEL SISTEMA INVETERADO DE ITINERANCIA AL ACTUAL SEDENTARISMO 
El cultivo del tomate de invierno, basado durante más de dos décadas en variedades llamadas de tipo «canario», se ha venido practicando tradicionalmente en sistema de itinerancia. El logro de altos rendimientos unitarios exigía una búsqueda constante de tierras vírgenes o, al menos, de aquéllas en las que no hubieran precedido aprovechamientos hortícolas. Resultaba antieconómico repetir el tomate sobre el mismo campo; a lo sumo el empresario arriesgaba una segunda cosecha, siempre aleatoria y con rendimientos inferiores en un 40 ó 50\%; en ello influían, entre otros factores, los hongos y nemátodos que infectaban el suelo a raíz de la cosecha inicial. Lógicamente al tomatero le interesaba cambiar de terreno a ser posible todos los años, lo cual era propiciado por el recurso a los arrendamientos de temporada.

Mediada la década de los setenta empezó a generalizarse la adopción de unas semillas híbridas, de origen usualmente holandés, que son resistentes, aunque no inmunes, a las plagas y enfermedades que alberga el suelo, y rinden cosecha netamente superiores y más precoces que el tomate «canario» al que han desplazado.

Tales híbridos han hecho viable la repetición prolongada del cultivo sobre el mismo campo, bien que secundados por tratamientos del terreno a base de desinfectantes -en especial el metan-sodio- que ya con anterioridad aplicaron algunas firmas apremiadas por la escasez de tierras vírgenes, aunque no lo hicieran sistemáticamente por cuanto la desinfección resultaba muy onerosa.

La combinación exitosa de híbridos y desinfección del terreno ha permitido que en 1983 una determinada sociedad lleva ya siete cosechas ininterrumpidas de tomate sobre la misma finca, camino de la octava plantación, sin que se produzca mengua del rendimiento esperado. [72]

Ello ha ido conduciendo a una sedentarización de las plantaciones (o, al menos, a asentamientos polianuales de las mismas) lo cual implica una utilización más compleja y racional de las potencialidades del suelo, e incluso, como corolario, de los recursos hídricos y de las ventajas que ofrece el clima, pues se están adoptando dos nuevas técnicas de producción: el riego localizado por goteo y los invernaderos, las cuales requieren unas inversiones cuantiosas que exigen una explotación prolongada de tales instalaciones, del orden de 6 y 8-10 años respectivamente.

Sin embargo, ha habido una fuerte inercia y grandes reticencias a romper el clásico nomadismo de las plantaciones; de hecho la mayoría de los tomateros, incluyendo a algunos de gran entidad, han persistido en él hasta fechas muy recientes. Y seguramente, quienes aún lo practican continuarán con el inveterado sistema mientras haya zonas que experimenten procesos de transformación al regadío, de los cuales se benefician los cosecheros exportadores que, o bien coadyuvan a bonificar los terrenos, a cuenta del rento, o sencillamente alquilan las fincas cuyo titular ha acondicionado, pero que todavía no explota. En opinión de los tomateros que así operan es menos costoso producir en tierra «nueva», la cual, por añadidura, siempre es más productiva que la desinfectada.

La exigüedad o, cuando menos, insuficiencia de tierras nuevas en el Camp d'Alacant -producto tanto de la mayor ocupación del suelo como de la penuria del agua- no constituye, a nuestro juicio, una variable independiente del proceso de fijación de los tomatales que, en mayor medida, ha tenido por escenario dicha comarca. Asimismo la prevalencia del sistema nómada en el Bajo Segura no es un fenómeno desconectado del auge que han estado experimentando las transformaciones al regadío, alentadas por el trasvase del Tajo y la explotación de ciertos acuíferos. Con todo, este proceso es contradictorio, pues precisamente el alud de bonificaciones y puesta en riego desembocará, al paso que las plantaciones de frutales ocupan esas tierras, en una oclusión de las oportunidades que hoy brindan a la horticultura del cosechero-exportador. (Quizás en un próximo futuro sean los invernaderos el único o, cuando menos, el principal sostén de la figura del horticultor, durante tanto tiempo en retirada ante la avalancha de la arborización.) 
Todo parece indicar que el paso a la fijación del cultivo obedece ante todo a razones de beneficio económico, traducidas en una serie de ventajas en cuanto a costos $\mathrm{y}$, especialmente, en el logro de mayores rendimientos. No hemos podido disponer de una contabilidad de los gastos asumidos bajo este sistema de explotación, pero resulta patente la existencia de muchos factores que juegan a su favor.

La itinerancia implica unas inversiones en la transformación y preparación del terreno y en obras inherentes a la conducción de las aguas para el riego, las cuales hay que afrontar en cada campaña y resultan cada vez más onerosas. Por contra, el cultivo sedentario, sobre todo si se acompaña del riego por goteo -como suele ser cada vez más habitual- ofrece muchas resultantes positivas. [73]

Este tipo de riego localizado sólo es factible si se prolonga el cultivo sobre la misma parcela, pues dada la considerable inversión inicial que requiere su instalación, hay que contar con un plazo largo para amortizarla.

El sistema de goteo implica numerosas ventajas. Reduce al mínimo el acondicionamiento del terreno, pues permite adaptarse a la topografía y prescindir de aterrazamientos, de nivelaciones y aun del trazado de caballones. Dado que el agua precisada por el tomatal se distribuye en un lapso de tiempo más prolongado, es suficiente disponer de un embalse pequeño, de poco costo. Todo ello posibilita que el terreno sea aprovechado al máximo, pues se gana para el cultivo alrededor del $20 \%$ de la superficie, que es lo que se estima que era ocupado por los grandes embalses, los taludes y márgenes de las terrazas y la red de acequias requeridos por el riego a manta.

Aparte de estas consideraciones, el factor más decisivo es que el goteo conlleva un aumento sustancial en los rendimientos unitarios de los tomatales, dado que racionaliza el aprovechamiento, por parte de la planta, no sólo del agua, sino también de los fertilizantes que se distribuyen con ella, con los consiguientes ahorros en ambos factores de producción, de los que ofrece mayor consideración el que atañe a los abonos, pues éstos inciden mucho más que el agua sobre el costo final del tomate.

Además de todas estas ventajas, la fijación sobre una parcela posibilita la práctica del no cultivo; una vez implantado el tomatal, con ayuda de la desinfección y del abonado intensivo del suelo, se puede prescindir de las labores y de las escardas (pues el metan-sodio también es herbicida), con lo cual la estructura de los caballetes de cañas tampoco es necesario renovarla. Por añadidura, la fijación en una zona determinada supone indudables ventajas operativas, así como economías en materia de transportes.

Todos estos condicionamientos explican que el número de empresas que sedentarizan la explotación se incremente de año en año, habiéndose incorporado muchas a este proceso en el transcurso de las dos o tres últimas campañas. En general se trata de firmas de entidad grande o mediana, mientras que el tomatero modesto suele continuar vinculado al método rotatorio.

A título de ejemplo de todo este proceso resulta significativo el caso de una empresa que se cuenta entre las pioneras del ramo. Empezó a producir el tomate de invierno en Novelda, donde instaló el primer almacén; sin dejar esta zona, lo cultivó también en Sant Joan y estuvo unos siete años en La Vila Joiosa (1959-65 ca.); después volvió al Camp d'Alacant, operando en este término y en los de Sant Joan, Mutxamel y El Campello, a la vez que lo hacía en La Murada, a raíz del alumbramiento de la Cava de los Suizos. Hoy tiene su almacén en Alacant y trabaja en su término, en la partida de Rebolledo, donde hacia 1970 entró en arriendo a largo plazo en una hacienda de más de 400 ha, en la cual ha permanecido hasta ahora, durante una larga etapa rotando el cultivo escalonadamente, para volver al cabo de unos siete años sobre las parcelas que ocupara al principio. Antaño, cuando producía tomate [74] «canario» llegó a cultivar más de un centenar de hectáreas en una campaña, pero en 1980 se limitaba a poco más de 40 ha, dado el mayor rendimiento de los híbridos. Finalmente, ese mismo año ensayó por 
primera vez la fijación del cultivo y desde la actual campaña, 1983-84, tiene toda la plantación sedentarizada con riego por goteo.

A nuestro entender, y pese a la mencionada persistencia relativa del itinerante, la tendencia hacia la explotación sedentaria es progresiva y parece irreversible.

En lo sucesivo, cuando aludamos a las variadas implicaciones del nomadismo cultural, debe entenderse que tales manifestaciones se corresponden más con el pasado -bien que muy próximo- y que en nuestros días están perdiendo vigencia aceleradamente. Así pues, en las páginas siguientes, el análisis del paisaje agrario modelado por los cosecheros exportadores de tomate se aborda desde una perspectica diacrónica -antes y después de la sedentarización- a fin de patentizar las consecuencias morfológicas, muy contrastadas por cierto, que conllevan uno y otro sistema de cultivo.

\section{REGÍMENES DE TENENCIA DE LA TIERRA}

La tradicional movilidad de las plantaciones ha corrido pareja con una forma muy transitoria, diríase que precaria, de apropiación de la tierra por parte del cosechero-exportador, consistente en un sistema de arrendamiento anual o, más propiamente, de campaña o de temporada, cuya práctica ha sido facilitada por la amplitud de las áreas geográficas en las que han ido actuando las compañías y por las antaño abundantes reservas de tierras vírgenes o de cultivo esporádico o marginal, propiciadas éstas, en gran medida, bien porque los propietarios carecen de medios para acometer su transformación en regadío, o bien porque practican un «barbecho social» ante la expectativa de pingües plusvalías generadas por los procesos de urbanización.

En líneas generales, el rento anual, que en los años cincuenta oscilaba entre 0,50 y 1 $\mathrm{pts} . / \mathrm{m}^{2}$, ahora fluctúa entre 2,50 y $6 \mathrm{pts} . / \mathrm{m}^{2}$, dependiendo de muchos factores, tales como la calidad y situación de la tierra, la disponibilidad de agua, etc., e incluso, si se trata de fincas recién transformadas en regadío pero aún no cultivadas por su titular, el canon puede alcanzar, en ocasiones, entre 7 y 10 pts. $/ \mathrm{m}^{2}$. Pero ese encarecimiento del rento es perfectamente asumible por el explotador, pues, de hecho, ha disminuido la participación del alquiler de la tierra en los costos de producción del tomate, la cual no llega siquiera al 3\%.

A medida que las firmas sedentarizan el cultivo se interesan manifiestamente por prolongar la tenencia de la tierra, no sólo mediante sucesivas renovaciones del contrato anual, sino también conviniendo arrendamientos a más largo plazo, en especial cuando se trata de instalar riego localizado o invernaderos, de modo que en la actualidad están proliferando los contratos de cinco a diez o doce años de duración. [75]

Si bien el recurso más socorrido es el alquiler de las tierras, ciertas compañías se decantaron hacia su consecución en propiedad. Son casos excepcionales, pero notorios, ya que esas firmas procedieron a gran escala, adquiriendo pacientemente numerosos predios, de preferencia contiguos, que por entonces se reducían a la condición de eriales y secanos marginales, hasta configurar unas haciendas que se cuentan entre las más descollantes de la provincia.

Fue así como, en los años cincuenta, la firma valenciana Fesa -una de las introductoras del tomate de invierno en el Camp d'Alacant- tomando como base un gran predio, antigua pertenencia decimonónica del barón de Benifayó, pudo acopiar gran parte de las 1.025 ha con que hoy cuenta la finca Lo Romero (casi toda en Orihuela), luego enajenada, en 1957, a la Compañía Valenciana de Cementos Portland, la cual la ha orientado hacia los frutales y cultivos en invernadero. De modo similar, otras dos pioneras del sector tomatero, Etasa y Bonny, han forjado sendos latifundios en los aledaños de L'Horta d'Alacant. La primera -hoy en situación económica precaria- durante la década de los sesenta logró reunir, después de 640 compras, cerca 
de 900 ha en la cañada del Vergeret (Alacant), la mayoría de ellas en coto redondo. En la actualidad, Bonny, S.A. es titular de vastas superficies, del orden de 600 ha en el Camp d'Alacant, las cuales fueron adquiridas a lo largo de dos decenios y aparecen distribuidas por los términos municipales de El Campello, Mutxamel y Sant Vicent del Raspeig.

Distinto es el caso de Lo Monte, hacienda del litoral oriolano, la cual, a fines del siglo pasado, estaba escindida en dos vastas propiedades de sendos aristócratas (marqués de La Puebla y condesa de Vía Manuel), y hoy conforma un coto redondo de 1.211 ha, cuyo titular, que la ha transformado al regadío en un 70\% -con ayuda de medieros y de una firma exportadora que se estableció a rento-, ha asumido directamente la explotación y, en parte, la comercialización. Posee cupo para exportar tomate, pero éste es un cultivo minoritario en la finca si se compara con las extensiones de frutales y de hortalizas diversas (tanto de calle como de invernadero). No es un ejemplo aislado; son varias las propiedades grandes cuyos dueños han pasado a integrar la manipulación y posterior venta de las cosechas propias, pero ninguna de ellas tiene una orientación tomatera prevalente.

Es importante resaltar que, a partir de la adopción de las variedades híbridas, se ha producido a modo de una progresiva liberación de las compañías respecto al factor tierra, por cuanto dichas variedades procuran unos rendimientos unitarios cada vez superiores. Ello juega a favor de todas las explotaciones tomateras, tanto de las nómadas como de las estables. Además, la irrefrenable tendencia a inmovilizar los tomatales contribuye a distraer mucho menos tierra que antaño, cuando los largos ciclos rotatorios suscitaban amplias reservas de barbechos. Ambas circunstancias -sedentarismo y mayor rendimiento- han permitido rebajar el umbral mínimo de superficie que, con miras a cubrir el cupo de exportación, e incluso para optimizar las economías de escala, precisa ineludiblemente cada empresa.

\section{[76]}

\section{LAS AGUAS PARA EL RIEGO, UN RECURSO ESENCIAL}

El agua es clave en este proceso. Por su rareza y carestía sólo los productos valiosos pueden rentabilizar su usufructo y con mayor razón su prospección, captación y trasvase a los campos. El cultivo del tomate requiere considerables capitales, del orden de más del millón y medio de pesetas por hectárea en cada campaña; de ahí que sea inconcebible arriesgar la plantación con agua insegura.

La situación de la zona, hoy como siempre, y pese al trasvase Tajo-Segura, es muy delicada por lo que respecta a los recursos hídricos. Éstos son un bien escaso en relación a las necesidades, además de estar mal distribuidos, y el peligro de la sequía se cierne a veces sobre la plantación. Asegurar esos caudales es de todo punto vital. Además suelen ser caros, oscilando hoy con frecuencia entre las 2.500 y 3.000 pesetas la hora (de $50 \mathrm{l} / \mathrm{s}$ ).

La exigencia de caudales por las plantaciones de tomate radica más en su cantidad que en su calidad, dado que es un cultivo que resiste bien, e incluso le favorece, un ligero contenido en cloruros, que prestan consistencia y tersura a la piel del fruto, aunque si aquél es excesivo mengua el peso y calibre del tomate y saliniza los terrenos. La estrategia de las compañías es, a ser posible, «jugar con toda la baraja», esto es, buscan la combinación o complemento entre los caudales de superficie y los hipogeos, e incluso mezclan los salinos con los de más calidad.

En el área de Novelda las firmas se beneficiaron de los débitos del Canal de la Huerta (acuífero de Villena) y de pozos locales, y en el Camp d'Alacant han aprovechado la trilogía de dotaciones de L'Horta (pantano de Tibi, Villena y Riegos de Levante), así como las de pozos, que con el tiempo hubo que alumbrar más lejos y a mayor profundidad, y a todo ello últimamente se han añadido las aguas residuales recicladas por la depuradora del Barranc de les Ovelles.

En el municipio de La Vila Joiosa los tomateros se instalaron a partir de 1958, atraídos 
por los caudales del pantano llamado «del Amadorio», recién construido sobre el Riu de la Vila, contribuyendo decididamente a la puesta en riego de vastas superficies; su retirada, iniciada hacia 1966, coincidió con una mengua aguda del nivel embalsado. En ciertas áreas favorables del «campo» del Bajo Segura la explotación de los acuíferos atrajo a muchas firmas. A partir de 1979 la llegada de las aguas del trasvase Tajo-Segura propulsó nuevas iniciativas, pero la actual inseguridad de sus dotaciones parece coartarlas.

Las compañías no suelen ser titulares de este factor de producción, pero hay notables excepciones, sobre todo entre las firmas dueñas de haciendas; los casos más notables son los de Bonny y Estasa, empresas que, además de alumbrar varios pozos en Aigües y en Busot, son partícipes de una sociedad que acometió la captación de importantes aforos en la Foia de Castalla, tras lo cual financiaron $27 \mathrm{Km}$ de conducciones de gran sección para llevar las aguas hasta sus dominios.

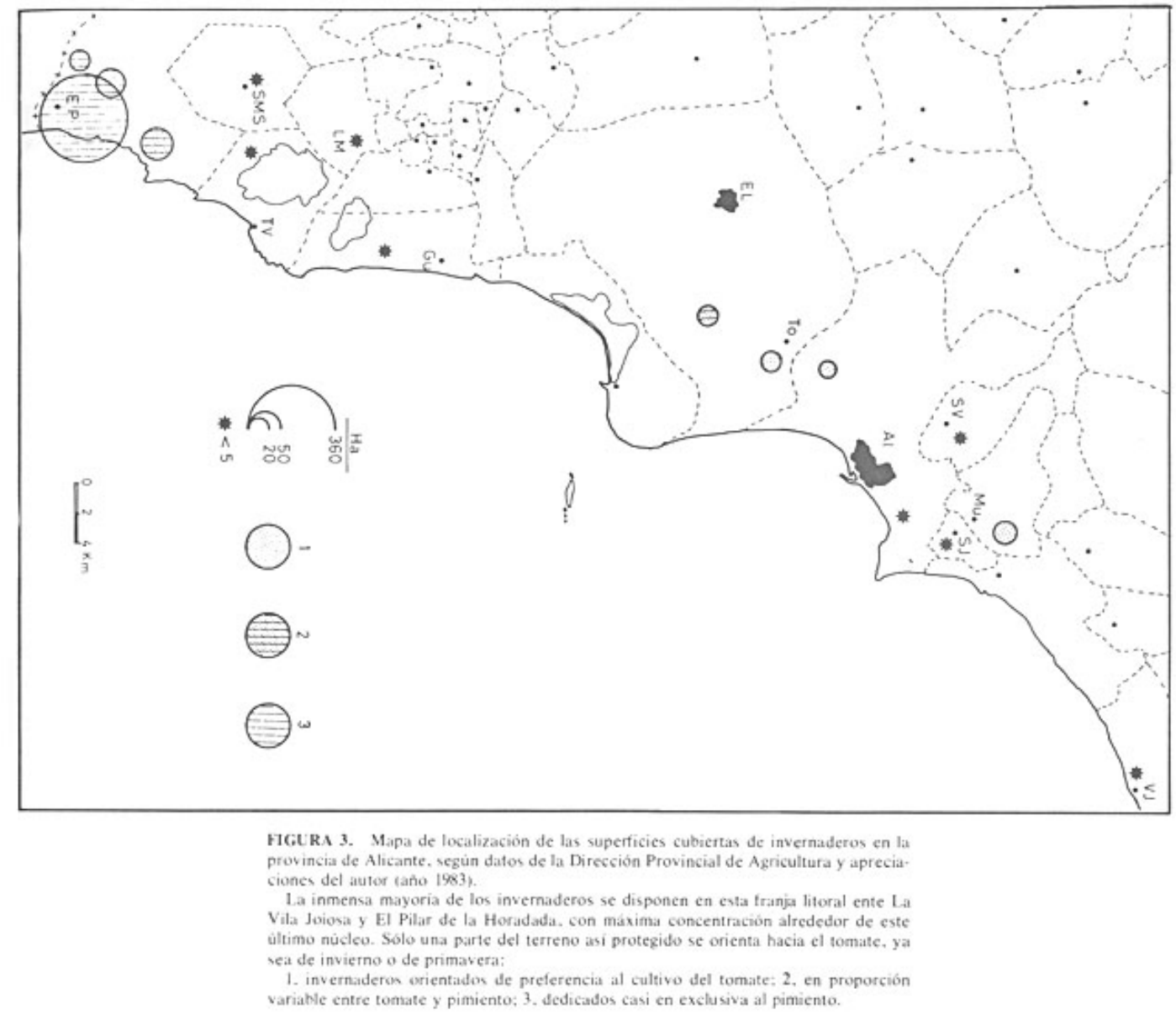

[77]

Aunque sin llegar a este extremo, la frecuente disociación entre las tierras arrendadas y los caudales disponibles obliga a los tomateros a afrontar importantes dispendios en canalizaciones, ya sean móviles o fijas, bien que en algún caso acometen perforaciones en los mismos campos a cultivar. Y si hay débitos excedentes, comercian con ellos.

Cuando se habla de irrigación, ésta es asociada comúnmente a una ocupación constante y densa del suelo. Pero la explotación itinerante de los cosecheros exportadores ha incumplido 
esta regla. El aprovisionamiento de agua había de programarse para una sola campaña, o para unas cuantas si se escalonaba o rotaba el cultivo por un mismo paraje. En cualquier caso, el tomatero nómada ha procurado minimizar las inversiones en una red de riego cuya utilización tenía que ser temporal; las conducciones se construían antaño a base de tubos de cemento o uralita ensamblados, susceptibles de desmontar y transportar con facilidad, peroúltimamente van siendo sustituidos por conductos de plástico, que ofrecen las mismas ventajas y son más baratos. A la siguiente campaña, bastaba con alargar la red de riego unos cientos de metros para dar servicio a los nuevos campos arrendados y plantados en la misma zona, y cuando se cambiaba de paraje, el tomatero levantaba las conducciones para utilizarlas en la nueva área de actuación.

En los últimos tiempos, en coincidencia con la sedentarización del cultivo, la red de riego deviene siempre estable, ya sea en las tierras arrendadas a largo plazo o en las haciendas propiedad de ciertas compañías.

Unos elementos de creciente significación económica y paisajística son los embalses, imprescindibles -en éste, como en otros cultivos- para que cada explotación organice el riego con independencia y racionalidad. Se trata de unas artesas, por lo general en parte excavadas y en parte construidas mediante diques de tierra, e impermeabilizadas con caucho butílico o bien con láminas de polietileno; si se desea prolongar la duración de éstas últimas, se recubren, a su vez, de arena, grava y piedras. Algunas de esas artesas aparecen rodeadas de una cerca metálica y con los taludes exteriores protegidos por plantas de porte rastrero para evitar su erosión. Precisamente, el primer embalse impermeabilizado en España con filme de polietileno se construyó, con $75.000 \mathrm{~m}^{3}$ de capacidad, en la finca Los Garroferos, de Benijófar (Bajo Segura).

Los embalses facilitan que cada explotación pueda estructurar su propia red de riego de forma totalmente autónoma, sin sujeción a turno o tandas, ni al insuficiente débito que proporcionan los pozos durante la extracción. Las grandes explotaciones, sobre todo las que son propiedad de las firmas, disponen de uno o dos vastos embalses «nodrizas», ubicados en una posición estratégica, topográficamente dominante, los cuales actúan como depósitos primarios de los caudales elevados desde los pozos o desde las arterias de las redes generales de riego (por ejemplo, en la zona al norte de Alacant hay un conjunto de esos nodrizas, que cubican entre 75.000 y $450.000 \mathrm{~m}^{3}$ cada uno). A cotas inferiores, repartidos por la finca, se sitúan pequeños embalses reguladores que se nutren de aquéllos, con lo que en todo momento se pueden atender prestamente las necesidades de agua de los distintos sectores de la explotación, [78] diferenciados éstos según niveles topográficos y/o según su orientación productiva.

El sistema de riego localizado por goteo (a veces automatizado), con acompañamiento de un regulador y la estación de control, está proliferando a ritmo cada vez más intenso en las explotaciones tomateras, al aire libre y en invernadero, pues reúne numerosas ventajas, ya referidas con anterioridad.

\section{LA MANO DE OBRA Y SUS MIGRACIONES TEMPORALES}

El del tomate sigue siendo un cultivo artesanal, que precisa de mucha mano de obra, la cual supone alrededor de tres cuartas partes de los gastos de cultivo. Además, el calendario laboral agrícola del sector aparece distorsionado, pues la mayor parte del trabajo se concentra en seis o siete meses, con fuertes puntas en determinadas épocas.

Las compañías han alentado importantes migraciones temporales con miras a superar tanto la escasez como la carestía de la fuerza de trabajo local. En parte, la rentabilidad del sector se sostiene merced a unos niveles salariales módicos.

Los trabajadores son reclutados sobre todo en las áreas rurales de Andalucía oriental, en especial las de Granada y Jaén, así como también en la zona interior de Murcia, en La Mancha e incluso en Extremadura. 
Acuden en grupos familiares, dado que todos los miembros en edad laboral se emplean en las tareas inherentes al cultivo y a la manipulación del tomate. Por lo general las firmas se encargan de alojarles, usualmente en viviendas vacantes alquiladas para tal fin, tanto rurales como de los núcleos cercanos a las plantaciones, corriendo a cuenta del empresario el desplazamiento hacia éstas de las cuadrillas de trabajadores. El hacinamiento es la regla habitual. Algunas compañías construyeron elementales barracones en sus campos y, en algún caso, fundaron una colonia o «barrio» de casas estandarizadas, dotado incluso de una serie de servicios sociales.

Muchos de esos temporeros acostumbran a regresar año tras año, para la campaña tomatera. Otros se han ido estableciendo en las poblaciones próximas a Alacant, tendiendo los varones a emplearse en otras actividades (construcción y servicios), mientras que las mujeres suelen continuar trabajando para el tomatero (recolección y manipulado en el almacén).

Por ello, y por la coyuntura actual de crisis y paro, últimamente las compañías pueden reclutar más personal en la propia zona de cultivo, por lo que las migraciones masivas de largo alcance, aunque no han dejado de ser importantes, sí han perdido parte de la enjundia que tuvieron antaño.

\section{LOS PAISAJES AGRARIOS MODELADOS POR LOS COSECHEROS EXPORTADORES}

Las estructuras y morfologías agrarias derivadas de la explotación tomatera [79] son heterogéneas y cambiantes con el tiempo, en función de la distinta capacidad económica de las compañías y de la evolución de las técnicas y sistemas de cultivo. El mayor gradiente diferencial se establece entre el clásico sistema itinerante y el nuevo sistema sedentario, bien que ambos presentan a su vez diversas variantes; así, es patente el contraste entre las explotaciones regadas a manta y aquéllas que cuentan con riego localizado, y aun lo es más el que separa el cultivo al aire libre y el de invernadero (a éste, minoritario pero con buenas expectativas, dedicamos más adelante una especial atención).

La progresiva estabilización de los tomatales, tras una prolongada etapa de nomadismo cultural, implica, en suma, toda una redefinición de las consecuencias agromorfológicas que conlleva el cultivo del tomate de invierno.

\section{El ciclo estacional del cultivo y la correspondiente mutación del paisaje}

Ciertos elementos de la morfología agraria producto de esta actividad son cambiantes a muy corto plazo, el determinado en cada campaña por el ciclo anual, o estacional, del cultivo.

Si la plantación se realiza sobre tierra nueva, previamente hay que prepararla, disponer la red de riego, proporcionarle el abonado de fondo y erigir los caballetes, tareas que por lo común se efectúan durante la primavera. Pero si se repite el cultivo, la estructura de los caballetes de cañas no se retira, sino que deviene en un nuevo elemento fijo del paisaje; del mismo cuelga el rastrojo de las tomateras de la anterior campaña, hasta que en abril o mayo se arranca y se quema, tras lo cual se recomponen los desperfectos del encañado. Un mes o cuarenta días antes de la plantación se procede a desinfectar el terreno.

Entre tanto, a fines de junio se preparan los cepellones o tacos en el semillero. A mediados de julio, o desde primeros de mes si la explotación es grande, se procede a trasplantarlos al campo, con una densidad aproximada de 1'6 plantas $/ \mathrm{m}^{2}$. En agosto es patente ya el verdear de las tomateras. Los riegos, abonado, tratamientos y otros cuidados se suceden sin pausa. Las tareas más trabajosas son las podas en verde (desronyat) y el enramado o entutorado de las guías de la planta sobre las cañas, todo lo cual ocupa más de la cuarta parte de los jornales 
de campo, en tanto que la recolección, a la que contribuye mucho personal femenino, sobrepasa un tercio de los mismos, y se escalona desde fines de septiembre hasta últimos de febrero o mediados de marzo.

Después, en el campo sólo quedan los caballetes y el rastrojo; si el cultivo no se repite, también son retiradas las cañas, para aprovecharlas en otro terreno que se habrá acondicionado durante esa primavera. Los tomates se transportan hasta el almacén, donde son seleccionados, clasificados por calibres y envasados en receptáculos de $6 \mathrm{Kg}$. La exportación del fruto alcanza incluso al cosechado en la segunda semana de febrero; el posterior únicamente se destina a la conserva y al consumo interior, al igual que los destríos de toda la campaña. [80]

Por tanto, ante el espectador se presentan unas mutaciones fisonómicas evidentes; entre agosto o septiembre y finales de febrero los tomatales aparecen como intensas manchas verdeantes, cuajadas de frutos; tapizado por esa vegetación, apenas es discernible el entramado de cañas, el cual a partir de marzo pasará a ser el elemento más manifiesto del paisaje en los tomatales sedentarios.

\section{Un ager muy peculiar, el asociado a la itinerancia}

En caso de que se trabaje en itinerancia -como se hizo siempre antaño- la estrategia de las compañías consiste en establecerse a rento en una zona dotada de un microclima favorable y que disponga de agua o sea accesible a sus fuentes de aprovisionamiento. Allí se ejecuta un proyecto concebido para varias campañas, rotando sobre campos colindantes o próximos entre sí. Si se trata de minifundios, cada explotación reúne varias propiedades en alquiler, a fin de organizar predios de adecuada dimensión; pero se prefiere una finca vasta, por la que desplazar el cultivo escalonadamente. Las firmas de mayor fuste simultanean varios de estos proyectos, actuando sobre diversas zonas, con miras a reunir tierras suficientes y diluir los riesgos climatológicos en la medida en que distancian las plantaciones de una misma campaña.

De esta actividad nómada surge un ager con un cultivo intensivo de grandes rendimientos, pero que ofrece unas características muy peculiares. Una de ellas es su discontinuidad; las plantaciones se reparten por toda la geografía en manchas aisladas, a modo de archipiélagos espaciados, con frecuencia rodeados de baldíos e incultos que, en parte, constituyen la reserva potencial para futuras actuaciones de los tomateros.

Otra nota es su fugacidad. Las roturaciones entran en un ciclo de operaciones agrícolas de larga rotación; de pronto las plantaciones parecen surgir de la nada, para extinguirse al año siguiente; tan sólo volverán si el suelo permanece en un prolongado descanso, entre seis y diez años.

Los confines entre el regadío y el secano son inestables. En frase de Deffontaines, «campo de cultivo y canal de riego -en la agricultura mediterránea- son propiedades que se refuerzan entre sí»; pero en estas latitudes lo usual es que el campo no pertenezca al cosechero-exportador, que es quien le proporciona el agua, ni ésta es propiedad del titular de la tierra; es más, aquél retirará las tuberías de riego que dispuso solamente para una campaña.

Antaño, en ocasiones el tomatal ocupaba los entreliños de ciertas plantaciones arbóreas de secano, que después el titular proseguía cultivando. Cuando las tierras arrendadas son yermos y secanos desheredados, tras la campaña tomatera los campos vuelven a la imagen de abandono y desolación que les caracterizaba anteriormente, aunque los nuevos aterrazamientos, sus tonalidades más blanquecinas, los caballones que los ondulan y la impronta de las boqueras y los sifones, continúan atestiguando la condición de ager intensivo que asumieron efímeramente. [81]

Pero en muchas ocasiones y en diversas zonas los agricultores han ido consiguiendo agua y transformando esos campos en regadíos con cultivos remuneradores, de forma que las tierras 
donde vegetó el tomate se convierten así en un ager permanente. Así ocurrió en el Vinalopó Mitjà y en Agost, donde sobre los barbechos dejados por los tomateros se instalaron plantaciones de viñedos para la uva de mesa, así como en La Vila Joiosa y en ciertas áreas del Camp d'Alacant, donde han sido beneficiados por la citricultura o, si el agua escasea o es cara, por plantaciones de almendros.

En estos casos, con frecuencia han sido las propias firmas tomateras quienes han contribuido decisivamente a estas transformaciones -que asumieron los propietarios agricultoresal instalar por su cuenta (o a cambio del rento) las redes de canalización del agua, tal como llevaron a cabo en La Vila Joiosa (riegos del Amadorio) o, más recientemente, en la cuenca de Busot, donde el ya citado trasvase de aguas hipogeas desde Castalla, a cargo de dos de esas firmas, además de beneficiar a la agricultura de la zona ha posibilitado la aparición de urbanizaciones de segundas residencias.

\section{La configuración de los campos}

En el supuesto de que la explotación sea itinerante, al tomatero no le interesa abordar costosos movimientos de tierras a la hora de preparar los campos. Los trabajos de desfonde y de preparación del terreno se acompañan de un abonado de fondo a base de basuras urbanas con mezcla de fertilizantes químicos. Si se trata de tierras nuevas, se procura la máxima adaptación a la topografía, bien mediante un abancalado somero, con gradas poco anchas, o bien se simplifica todavía más, pues no se abancala sino que se riega «a cota-nivel», por canales y boqueras cuyo sinuoso trazado se corresponde con el de las isohipsas.

Cuando el sistema de riego es el tradicional, a manta, además de proceder a una nivelación cuidadosa de las distintas secciones del terreno, la preparación del mismo exige también una micromodelación del campo a base de surcos y caballones sobre los que se levantan los armazones de cañas. Pero ahora, el riego localizado permite prescindir de ese micromodelado, para erigir en llano los caballetes.

En la circunstancia, más excepcional, de que la sociedad posea fincas propias, sí se ha procedido a una remoción y reestructuración completa del terreno, con trazado de amplias terrazas. A su vez, esos bancales grandes se suelen dividir en porciones o «cuadros», que van separadas por unos bancos de tierra, los cuales facilitan la circulación de los operarios y de las máquinas. Todo ello, unido a la nueva red caminera, impregna a esas explotaciones de una geometría muy singular.

Estos amplios y costosos aterrazamientos se gestaron cuando en el sector tomatero no se había planteado todavía la conveniencia del riego localizado. Actualmente, en la medida en que se instala el riego por goteo, huelgan esas [82] onerosas transformaciones, pues lo que procede es eliminar las antiguas terrazas, cuando las hay, borrando sus márgenes y taludes, a fin de ganar superficie para la plantación; el terreno «recobra» así su pendiente natural.

Si no existen tales bancales, simplemente se atienen a un estricto acomodo a las condiciones topográficas; la regularización de las mismas es muy somera, de forma que las pendientes conservan prácticamente su primitivo estado; cada hilera de caballetes puede alzarse sobre una cota distinta, siguiendo -junto con las correspondientes gomas de riego- una determinada curva de nivel.

En ciertos casos el cosechero-exportador hace una campaña de tomate sobre un terreno a rento recién transformado y abancalado por su propietario, pero que todavía está desnudo o tiene un arbolado muy embrionario.

Siempre que se trabaja sobre tierras en arrendamiento, como es habitual, las nuevas unidades de explotación no suelen coincidir con las parcelas catastrales o de propiedad; es más, a menudo ni siquiera se corresponden con las parcelas visibles o fisonómicas preexistentes, 
puesto que las antiguas graderías de pequeños bancales son eliminadas -como queda dicho- al instalar el riego por goteo.

El recurso a los híbridos y a la desinfección del terreno está dando como resultado la consolidación de unos paisajes agrarios más estables y elaborados que los que atañían al cultivo rotatorio. Paisajes que, con frecuencia, surgen como auténticos oasis de gran intensidad agrícola en nítido contraste con un entorno desnudo, apenas salpicado por el ralo matorral xérico o por algún aprovechamiento extensivo de secano, bien que otras veces quedan inmersos entre plantaciones de cítricos o en vecindad con otras explotaciones hortícolas.

La explotación más intensa del paisaje se ha dado allí donde algunas compañías accedieron a la titularidad de las tierras. Cuando éstas fueron acopiadas, a base de una multiplicidad de compras, a un mosaico parcelario anárquico y variopinto, sucede un coto redondo, y si bien éste presenta -a tenor de su génesis- un perímetro catastral muy caprichoso y deforme, incluso con pequeños enclaves de propiedad ajena, lo cierto es que en el conjunto de la hacienda se fragua una planificación que hace tabla rasa de lo heredado (linderos, bancales, arbolado...) e impone una imagen de regularidad y geometría. En esas circunstancias se observa una estrategia tendente a diversificar los aprovechamientos. Así, el proyecto de Etasa, antes de su crisis financiera, consistía en distribuir su hacienda de El Vergeret, de unas 900 ha, entre un tercio de cítricos, otro de viñedo de uva de mesa y el tercero de frutales primerizos y tomates. Por su lado la firma Bonny, propietaria de alrededor de 600 ha en el Camp d'Alacant, aunque continúa esencialmente dedicada al tomate, cuenta con una extensa plantación de vides en parral, cultivando además diversas hortalizas, así como nectarinas y otros frutales.

\section{LOS INVERNADEROS, UNA ALTERNATIVA PARA EL SECTOR TOMATERO}

Los invernaderos -«cierros» en Canarias- son naves compuestas por una [83] estructura, bien de rollizos de madera (los de tipo «parral») o bien metálica, sostén de una cubierta de plástico (polietileno) que cierra un espacio, accesible al hombre y a la maquinaria, y procura unas condiciones ambientales idóneas para obtener cosechas fuera de estación, con el único concurso del sol como fuente calorífica (que es lo usual en esta zona donde se sobrepasan las 3.200 horas de iluminación al año). Además de viabilizar los cultivos extratempranos o anormalmente tardíos, el recurso a variedades selectas y los cuidados intensivos aseguran, en este medio favorable, altos rendimientos unitarios y calidades excepcionales.

El módulo de invernadero más usual es el de $2.000 \mathrm{~m}^{2}$ de superficie abrigada, bien que puede oscilar entre 100 y 2.500 ; de forma rectangular, el ancho suele ser de 10 metros o poco más a fin de facilitar, junto con las labores, la aireación del interior cuando las condiciones térmicas e higrométricas así lo requieran.

Los invernaderos de implantación más antigua (El Pilar) se regaban a manta, pero con el tiempo se han ido generalizando los sistemas de riego localizado con los que se logran mayores producciones por unidad de superficie; en la zona tomatera lo usual es el riego por goteo y, en algún caso, por aspersión.

En la zona de El Pilar, como en todas las llanuras litorales, los invernaderos no plantean problemas de localización, pero en áreas de topografía irregular hay que ubicarlos en función de los microclimas. De preferencia se escogen laderas de sierras o montículos orientados a mediodía, con máxima insolación invernal y protegidos de los vientos del N. Ello siempre que las condiciones edáficas lo permitan. Tan esencial como la luz es la ventilación: los emplazamientos deben gozar de una aireación óptima tal que permita controlar la higrometría en el interior del abrigo (una condensación que acumule densos vahos en el techo del mismo denuncia una deficiente renovación del aire), pues hiperhumedad y calor es el mejor caldo de 
cultivo para los agentes fitopatógenos. Por ello rehuyen las vaguadas u hondos demasiado cerrados, aunque coincidan con los mejores suelos.

Introducida a modo de efecto de propagación espacial desde Almería, esta técnica de cultivo protegido ha cobrado difusión en las comarcas sureñas de la provincia (así como en el NE del vecino Campo de Cartagena) y los dos aprovechamientos prevalentes corresponden al pimiento y al tomate. El primero acompañó a la introducción del invernadero a partir de 1971 en la zona de El Pilar de la Horadada (Orihuela) y viene ocupando desde entonces alrededor del $85 \%$ de la superficie cubierta; el resto se cultiva de tomate, melón, pepino, judía y otras hortalizas. Aquí, el tomate, bien que con altibajos, siempre ha sido el segundo cultivo en extensión, y en los últimos años supuso en torno al 6\% del suelo invernado.

Los invernaderos que rodean a El Pilar, o bien son instalados por propietarios medios y pequeños, y se benefician preferentemente en exploración directa [84] y familiar, o bien los montan algunos terratenientes e inversores que los ceden en aparcería u otros regímenes de tenencia indirectos. Según el fichero de socios de la Sociedad Agraria de Transformación local, el $85 \%$ de la propiedad invernada es menor de 1,5 ha, siendo la media global de 0,88 ha/propietario. La mencionada S.A.T. es la encargada de manipular y comercializar el grueso de la producción de los invernaderos. Por consiguiente, la actuación aquí de las compañías exportadoras es prácticamente nula (vide COSTA, J. y CANALES, G.: «El cultivo en invernadero y la comercialización agraria en Orihuela y Campo de Cartagena», Cuadernos de Geografía, 27, Valencia, 1980, pp. 173-201).

A partir del foco de El Pilar, después de 1974, los invernaderos se difundieron por otros ámbitos del Bajo Segura, principalmente hacia el norte, sobre una franja costera (máximo hasta unos $8 \mathrm{Km}$ del mar); primero lo hicieron sobre grandes fincas del área litoral oriolana y próximas a El Pilar (Lo Romero, Lo Monte, Campoamor), y luego, por el término de Guardamar y, en menor medida, por San Miguel de Salinas y Los Montesinos (sur de Almoradí). El canal del trasvase Tajo-Segura ha propiciado el asentamiento de nuevos invernaderos, a partir de 1979, en el tramo al sur de San Miguel y hasta el límite provincial, muchos de ellos sobre tierras recién transformadas, mientras que en el sector interior del trasvase, el canal de Crevillent también auspiciaba otro pequeño núcleo de invernaderos en el área de La Murada (Orihuela), alejados de la costa, pero dispuestos sobre un glacis a cubierto de vientos fríos y con buena exposición e insolación. En todos esos lugares, a medida que se distancian de El Pilar, aumenta la orientación tomatera en la superficie cubierta. Muchos de esos invernaderos han sido instalados $\mathrm{o}$, almenos, son explotados por firmas tomateras de variada envergadura o por terratenientes que asumen la comercialización.

El fenómeno del invernadero presenta otro foco en el Camp d'Alacant que, si bien es mucho menos importante que el de El Pilar, presenta el interés, para nuestro tema de estudio, de que la iniciativa corresponde aquí mayoritariamente a las firmas tomateras. En esta comarca la adopción de esta técnica es aún más reciente; data de hace unos 4 ó 5 años, como máximo 7 , coincidiendo precisamente con la del tomate híbrido. A excepción de Bonny (unas 20 ha), las superficies invernadas oscilan entre $4.000 \mathrm{~m}^{2}$ y 5 ha por empresario; muchos de éstos partieron de la posición de modestos agricultores y del recurso al crédito y hoy gozan de un alto cupo exportador basado en el tomate producido exclusivamente bajo cubierta. Las mismas características presenta el conjunto de invernaderos de Torrellano, en Elx, pero contiguo al anterior, mientras que en otras partidas ilicitanas los hay -más dispersos y casi todos montados después de 1980- a cargo de agricultores que comercializan a través de grupos cooperativos.

En general los invernaderos de las comarcas de Alacant y Elx, como se deduce de lo anterior, están orientados de preferencia al cultivo del tomate, aunque son bastantes los que en el presente año los comparten con pimiento. [85] El tomatero puede escoger entre la cosecha de invierno o la de verano, o bien producir tomates en ambas estaciones a la vez, en distintos 
invernaderos; algunos incluso fuerzan dos cosechas por año, pero son los menos.

El ciclo de invierno se inicia en agosto o septiembre con la plantación, prolongándose la cosecha desde diciembre o enero hasta marzo o incluso abril, y el de primavera se cumple entre diciembre o enero y la recolección que se espacia desde marzo a julio o agosto.

El mantener ambos ciclos a la vez en una batería de invernaderos resulta interesante con vistas a dosificar la vertiente comercial y dar continuidad al trabajo en el almacén de manipulación. Por las mismas razones las cosechas protegidas pueden complementarse bien con la cosecha de calle o al aire libre. Estas consideraciones son las que, junto a las perspectivas de los mercados extranjeros e interiores, aquilata el empresario a la hora de decidir las superficies que en cada campaña dedica al tomate de uno y otro ciclo (en el presente año, p. ej., el fruto de primavera dio un pésimo resultado comercial).

En cualquier caso los rendimientos del tomate protegido son netamente superiores al de calle; las empresas bien preparadas obtienen, con riego por goteo, entre 14 y $16 \mathrm{Kg}$ por m² de superficie cubierta.

Los invernaderos introducen un nuevo elemento formal en el paisaje agrario. Por lo general una explotación asocia varios módulos o naves de invernadero, de 1.700 a $2.500 \mathrm{~m}^{2}$ cada uno, a fin de cubrir superficies mayores, susceptibles de generar economías de escala. El acoplamiento de los módulos sobre el terreno se produce usualmente disponiendo una calle rectilínea -que sirve de acceso y facilita la ventilación-, la cual, si la topografía no es llana, desciende ladera abajo (flanqueada por dos regatas que encauzan las aguas de escorrentía). A ambos lados de la misma se disponen sendas baterías de naves paralelas, que dejan entre sí estrechos pasillos, convenientemente escalonadas siguiendo las curvas de nivel; y todo ello queda dominado por el embalse regulador y la estación de filtrado y control.

El conjunto destaca siempre por la blancura del plástico y la luz que el mismo refleja, contrastando con las tonalidades ocres o rojizas de la tierra o incluso emergiendo entre una masa forestal (p. ej., los pinares de la zona de Río Seco). Sólo en El Pilar constituyen un auténtico mar de plástico, casi sin solución de continuidad. El parcelario preparado para acoger estas estructuras denota asimismo una especial geometría -como lo patentiza la fotografía aérea- a modo de una apretada retícula de pequeños campos rectangulares.

\section{BIBLIOGRAFÍA}

El acopio de información se debe ante todo al trabajo de campo y al acercamiento personal a empresarios, técnicos y trabajadores, a quienes expresamos [86] nuestro sincero agradecimiento. También ha sido provechosa la consulta de los siguientes estudios:

BROTONS BOIX, A.: El cultivo del tomate en la provincia de Alicante, Memoria de licenciatura, Alicante, Departamento de Geografía, 1978, 218 pp. (inéd.).

GABINETE TÉCNICO DEL CONSEJO ECONÓMICO-SOCIAL: Tomate de invierno, Alicante, Organización Sindical, 1973, 135 pp.

GARCÍA MORATO, M. A.: Cultivo del tomate de invierno en el sureste español, Madrid, Publicaciones de Capacitación Agraria, 1969, 75 pp.

NAVARRO SALA, J. A.: Producción y exportación del tomate, Alicante, Servicio Comercial de Cosecheros Exportadores de Tomate, 1966, 155 pp.

VILLALBA MORENO, E.: «El cultivo del tomate en Canarias», en Los paisajes rurales en España, Valladolid, Asociación de Geógrafos Españoles, 1980, pp. 343-350. 